\title{
Effects of flooding on grafted annona plants of different scion/rootstock combinations
}

\author{
Xin-Yu Fu ${ }^{1}$, Song-Xing Peng ${ }^{1}$, Shuai Yang ${ }^{2}$, Yong-Hui Chen ${ }^{2}$, Jing-Yi Zhang $^{1}$, Wei-Ping Mo ${ }^{1}$, \\ Jian-Yun Zhu ${ }^{3}$, Yao-Xiong $\mathrm{Ye}^{3}$, Xu-Ming Huang ${ }^{1^{*}}$ \\ ${ }^{1}$ Physiological Laboratory for South China Fruits, College of Horticulture, South China Agricultural University, Guangzhou, China; \\ ${ }^{*}$ Corresponding Author: huangxm $@$,scau.edu.cn \\ ${ }^{2}$ Dongguang Humen Agricultural Science and Technology Extension Center, Dongguan, China \\ ${ }^{3}$ Dongguan Forestry Research Institute, Dongguan, China
}

Received 2 November 2011; revised 18 December 2011; accepted 20 January 2012

\section{ABSTRACT}

Annona atemoya Hort cv. African Pride (AP) is highly valued due to its high quality and unique flavor, but highly susceptible to water-logging. Prevalence of root diseases in saturated soils is one of the main problems in production, which restricts the development of AP in south China, where flooding frequently occurs in rainy seasons. However, some annona species, e.g. $A$. montana, $A$. glabra and $A$. muricata, are relatively tolerant to continuous flooding and periodic water-logging conditions, but of limited commercial value. Yet, the potential may exist to increase flood tolerance of commercial annona varieties by the use of flood tolerant rootstocks. An experiment was conducted with the aim to study the effects of continuous or periodical soil flooding on tree performances of four different annona scion/rootstock combinations: APIAR/G (scion/interstock/rootstock), AR/G (scion/rootstock), APIAR/M and AR/M, where AP stands for Annona atemoya Hort cv. African Pride, AR for the hybrid of "AP" atemoya $\times A$. reticulata, used as an interstock, $G$ for pond apple (A. glabra), and $M$ for mountain soursop (A. montana). Plant growth, leaf net photosynthetic rates and chlorophyll fluorescence parameters were measured regularly after flooding treatments were applied. Flooding treatments reduced shoot extension, leaf production, net photosynthetic rates and maximum quantum efficiency of photosystem II $\left(F_{v} / F_{m}\right)$ in plants of APIAR/M and AR/M, which displayed wilting within 2 weeks of flooding, with a higher wilting percentage in APIAR/M than in AR/M. The wilted plants shed all leaves but remained alive and sprouted new but weak shoots after 16 weeks of flooding. Long term flooding did not suppress but enhanced photosynthesis as well as tree growth in APIAR/G and AR/G, with vigorous growth of adventitious roots. Thus, we suggest the use $A$. glabra instead of $A$. montana as a rootstock and AR as an interstock to increase flood tolerance of commercial annona varieties.

Keywords: Annona; Rootstock; Interstock; Flood Tolerance; Photosynthesis

\section{INTRODUCTION}

Soil flooding is a common environmental stress in wetland and in areas with high rainfall, poor soil drainage and high water table fluctuations, inducing changes in soil physicochemical properties by altering soil structure, depleting oxygen, accumulating carbon dioxide, producing anaerobic decomposition of organic matter, and reducing the availability of iron and manganese [1,2]. The main effects of soil flooding on woody plants are inhibition of photosynthesis and absorption of macronutrients, alterations in hormonal balance and dry mass partitioning, and advancement in plant senescence, causing suppression of shoot and root growth or even tree death $[3,4]$. However, flood tolerance varies greatly with plant species and rootstocks [2]. In order to efficiently maintain agricultural production in areas subjected to water logging, it is always desirable to identify flood tolerant crops, including fruit trees with economic potential.

Commercial annona varieties, such as cherimoya (Annona cherimola Mill.), sugar apple (A. squamosa L.) and atemoya (A. squamosa $\times A$. cherimola), are generally grown on seedling rootstocks, which are very susceptible to water-logging [5,6]. Even for short periods, flooding reduces net carbon dioxide assimilation and vegetative growth of flood sensitive Annona species [7]. A. atemoya Hort cv. African Pride (AP) was introduced 
to China in the 1980 's, and became popular due to its high quality and unique flavor. Prevalence of root diseases in wet soils is one of the main problems in AP production, which restricts its development in South China, where rainfall is plenty and flooding frequently occurs.

It was found that seedlings of some annona species, e.g. A. montana, A. glabra and A. muricata are tolerant to continuous flooding and periodic water logging conditions [7-10], but these species are of limited commercial value. Yet, potential may exist to increase flood tolerance of commercial varieties by the use of flood tolerant rootstocks [6,9]. However, many commercial annona species, such as atemoya are not graft-compatible with A. glabra or A. montana. Graft compatibility can be achieved with the use of interstocks that are compatible with both the scion and the rootstock $[7,8]$. Some studies showed that commercial annona species and cultivars grafted onto $A$. glabra rootstock thrived in periodically flooded wetlands $[7,9]$.

Notwithstanding, flood tolerance of different annona scion/rootstock and scion/interstock/rootstock combinations under continuously flooding and periodically flooding were not studied. In this study, an experiment was conducted to identify scion/rootstock combinations that can tolerate a high water table environment and maintain crop growth. The effects of soil flooding on vegetative growth, morphological changes in shoot and root and photosynthetic performance of AP plants grafted onto $\mathrm{G}$ (A. glabra) or M (A. montana) via an interstock of "AP" atemoya $\times A$. reticulata were examined.

\section{MATERIALS AND METHODS}

\subsection{Materials}

The study was conducted from July to November 2010 in the open field at the Education Center of the South China Agricultural University in Guangzhou, Guangdong, China $\left(23^{\circ} \mathrm{N} 113^{\circ} \mathrm{W}\right)$. Four annona scion-rootstock combinations were used: AP/AR/G (scion/interstock/rootstock), $\mathrm{AR} / \mathrm{G}$ (scion/rootstock), $\mathrm{AP} / \mathrm{AR} / \mathrm{M}$ and $\mathrm{AR} / \mathrm{M}$, where AP is short for Annona atemoya Hort cv. African Pride, AR is a hybrid of "AP" atemoya $\times A$. reticulata, $\mathrm{G}$ represents pond apple (A. glabra), and $\mathrm{M}$ stands for mountain soursop (A. montana). All grafted trees were one year of age since their final grafting and transplanted on March 25, 2010 into $15 \times 25 \mathrm{~cm}$ plastic pots with gravelly loam soil, which is native to southern China.

\subsection{Treatments}

Plants were subjected to continuous flooding, periodic flooding or normal irrigation (control) outdoors. For flooding treatment, the potted plants were separately put into a larger pot filled with water so that the entire root system was fully submerged under water. The continuous flooding experiment lasted for 16 weeks from July to November 2010, while periodic flooding experiments were conducted with alternative 2 weeks' flooding period and 2 weeks' non-flooded recovery. During the recovery periods, the potted plants were removed from flooding containers, drained, and then placed in the same conditions as the control plants. During the flooding periods, water was added to replace loss due to evaporation and transpiration so that the entire root system was continuously under water. Normal water conditions were maintained by irrigating the non-flooded plants with about $500 \mathrm{ml}$ of tap water daily. Treatments were arranged in a randomized complete block design, with 13 single-plant replicates in each of the scion/rootstock combinations.

\subsection{Growth Measurements}

Before flooding, synchronized new shoots were encouraged by pruning and defoliating a mature branch of each plant, as a means to eliminate the inhibitory effect on bud break due to the presence of leaves [7]. The new shoots were tagged for measurements of growth and leaf production, which were recorded every 4 weeks after initiating. Desiccation of the shoot apex, bending of stem, flagging of mature leaves were considered as symptoms of plant wilting. Plant wilting rate was recorded for all treatments biweekly from Week 1 (1 week after flooding was initiated) until Week 9, after which no more wilting plant occurred. On Week 4 and Week 16, four trees from each treatment were uprooted and the root systems were carefully washed and photographed.

\subsection{Photosynthesis and Chlorophyll Fluorescence Measurements}

Leaf gas exchange was measured between 07:00 am and 10:00 am, using a portable photosynthesis measuring system LI-6400 (Li-Cor Inc., Nebraska, USA). Measurements were taken from two mature leaves (fully exposed leaves located at the 6th or 7th node above the shoot basal), of three plants per treatment throughout the experiment. During measurements, the photosynthetic photon flux density (PPFD) was adjusted to $1000 \mu \mathrm{mol}$. $\mathrm{m}^{-2} \cdot \mathrm{s}^{-1}$, and the rate of air flow into the leaf chamber was set at $500 \mathrm{ml} \cdot \mathrm{min}^{-1}$. Net photosynthetic rate $(\mathrm{Pn})$ was measured periodically at $0,1,2,3,4,8,12$ and 16 weeks after flooding treatments were imposed.

Chlorophyll fluorescence was measured with the same leaves between 07:00 am and 10:00 am at Week 0, 1, 2 and 3, using a pulse-modulated fluorometer (FMS2, Hansatech, UK.). Leaves were adapted in the dark for $20 \mathrm{~min}$ prior to chlorophyll fluorescence measurement. The maximum quantum efficiency of the photosystem II $\left(\mathrm{F}_{\mathrm{v}} / \mathrm{F}_{\mathrm{m}}\right)$ 
was determined as $\mathrm{F}_{\mathrm{v}} / \mathrm{F}_{\mathrm{m}}=\left(\mathrm{F}_{\mathrm{m}}-\mathrm{F}_{0}\right) / \mathrm{F}_{\mathrm{m}}[11]$.

\subsection{Statistical Analysis}

Data was subjected to analysis of variance (ANOVA) using SPSS statistical software to test for significance of main effects followed by LSD multiple range tests.

\section{RESULTS}

\subsection{Effect of Flooding on Shoot Growth}

None of the flooded $\mathrm{AP} / \mathrm{AR} / \mathrm{G}$ and $\mathrm{AR} / \mathrm{G}$ plants as well as control plants showed wilting, while flooded AP/ $\mathrm{AR} / \mathrm{M}$ and $\mathrm{AR} / \mathrm{M}$ showed slight wilting with a wilting rate of $30.7 \%$ and $7.6 \%$ respectively by Week 1 . The wilting percentage of $\mathrm{AP} / \mathrm{AR} / \mathrm{M}$ and $\mathrm{AR} / \mathrm{M}$ plants continued to increase in both the continuous flooding and periodic flooding treatments, with the highest wilting percentage of $84.6 \%$ and $38.4 \%$ by Week 7 , respectively (Table 1). During the flooding periods, the wilting percentage of $\mathrm{AP} / \mathrm{AR} / \mathrm{M}$ was much higher than that of AR/M (Table 1).

$\mathrm{AP} / \mathrm{AR} / \mathrm{M}$ and $\mathrm{AR} / \mathrm{M}$ plants showed signs of stress under flooding. AP/AR/M plants had more severe stress symptoms than AR/M plants (Figure 1). By Week 4, all

Table 1. Wilting percentages of plants of different rootstock and scion combinations under non-flooded conditions, continuous and periodic flooding.

\begin{tabular}{cccccc}
\hline \multirow{2}{*}{ Flooding treatment } & \multicolumn{5}{c}{ Wilting percentage (\%) } \\
\cline { 2 - 6 } & Week 1 & Week 3 & Week 5 & Week 7 & Week 9 \\
\hline Continuous flooding & & & & & \\
AP/AR/M & 30.7 & 46.1 & 76.9 & 84.6 & 84.6 \\
AR/M & 7.6 & 23 & 30.7 & 38.4 & 38.4 \\
AP/AR/G & 0 & 0 & 0 & 0 & 0 \\
AR/G & 0 & 0 & 0 & 0 & 0 \\
Periodic flooding & & & & & \\
AP/AR/M & 23 & 53.8 & 69.2 & 84.6 & 84.6 \\
AR/M & 7.6 & 23 & 38.4 & 38.4 & 38.4 \\
AP/AR/G & 0 & 0 & 0 & 0 & 0 \\
AR/G & 0 & 0 & 0 & 0 & 0 \\
Non-flooded & & & & & 0 \\
AP/AR/M & 0 & 0 & 0 & 0 & 0 \\
AR/M & 0 & 0 & 0 & 0 & 0 \\
AP/AR/G & 0 & 0 & 0 & 0 & 0 \\
AR/G & 0 & 0 & 0 & 0 & 0 \\
\hline
\end{tabular}

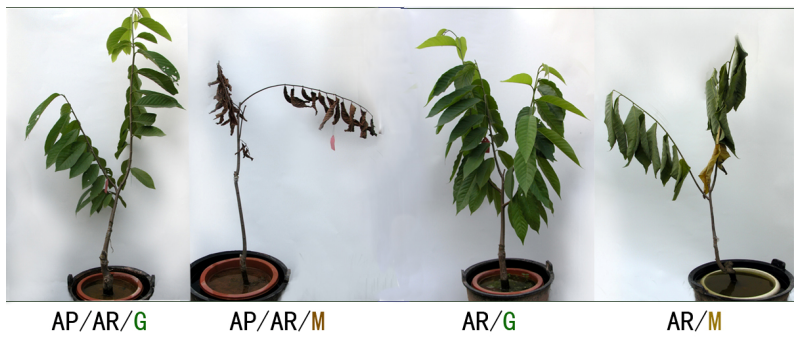

Figure 1. Vegetative growth of four annona scion/rootstock combinations after 4 weeks of continuous flooding.

the leaves in the wilting plants of $\mathrm{AP} / \mathrm{AR} / \mathrm{M}$ had become dry and brown, while the wilting plants of AR/M preserved some green leaves (Figure 1). The wilted plants shed all leaves eventually, but they remained alive and had produced new, but weak shoots by Week 16. However, flooding treatments did not cause all plants of $\mathrm{AP} / \mathrm{AR} / \mathrm{M}$ and $\mathrm{AR} / \mathrm{M}$ to wilt. In those non-wilted plants, bud break occurred at Week 16, followed by sluggish shoot elongation and leaf expansion.

Shoot elongation and leaf production were traced in the non-wilted AP/AR/M and AR/M plants and in each of the $\mathrm{AP} / \mathrm{AR} / \mathrm{G}$ and $\mathrm{AR} / \mathrm{G}$ plants. By Week 4, continuous flooding and periodic flooding had significantly suppressed shoot extension and leaf production in AP/AR/M plants, reducing them by about $90 \%$ compared to the non-flooded plants (Figure 2). In AR/M plants, continuous flooding significantly reduced shoot extension and leaf production by about $50 \%$, and periodic flooding significantly reduced shoot extension by about $30 \%$ but only slightly reduced leaf production (Figure 2). Shoot extension and leaf production in $\mathrm{AP} / \mathrm{AR} / \mathrm{G}$ plants declined slightly by about $20 \%$ when exposed to continuous flooding, and was basically unaffected when exposed to periodic flooding. There was no significant effect of either continuous or periodic flooding on shoot extension and leaf production in $\mathrm{AR} / \mathrm{G}$. The results suggested that there were strong interactions between rootstock and scion in response to flooding.

When shoot growth and leaf production were further traced in $\mathrm{AP} / \mathrm{AR} / \mathrm{G}$ and $\mathrm{AR} / \mathrm{G}$ plants, it was found that shoot extension and leaf production in these plants was enhanced by flooding (Figure 3). By Week 16, leaves of AR/G exposed to continuous flooding had gradually outnumbered the control plants by $20 \%$.

\subsection{Effect on Root Morphology}

After 4 weeks of continuous flooding, AP/AR/G and $\mathrm{AR} / \mathrm{G}$ plants developed abundant adventitious roots (Figure 4), which were white and vigorous. In contrast, $\mathrm{AP} / \mathrm{AR} / \mathrm{M}$ and AR/M had a poor black-brown root system, and neither of them produced new roots (Figure 4).

At week 16, the root systems of $\mathrm{AP} / \mathrm{AR} / \mathrm{G}$ and $\mathrm{AR} / \mathrm{G}$ 


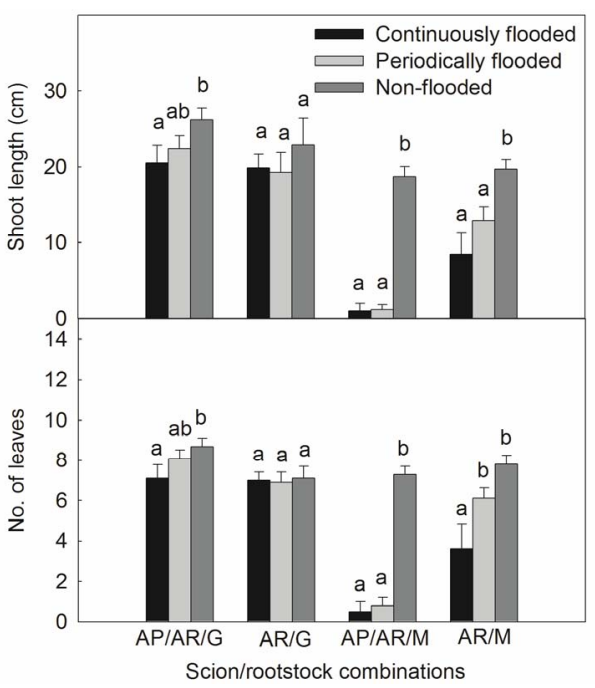

Figure 2. Shoot growth of four annona scion/ rootstock combinations in response to continuous and periodic flooding (on Week 4). Different letters indicate significant differences between flooding treatments according to LSD test $(\mathrm{P}<0.05)$.

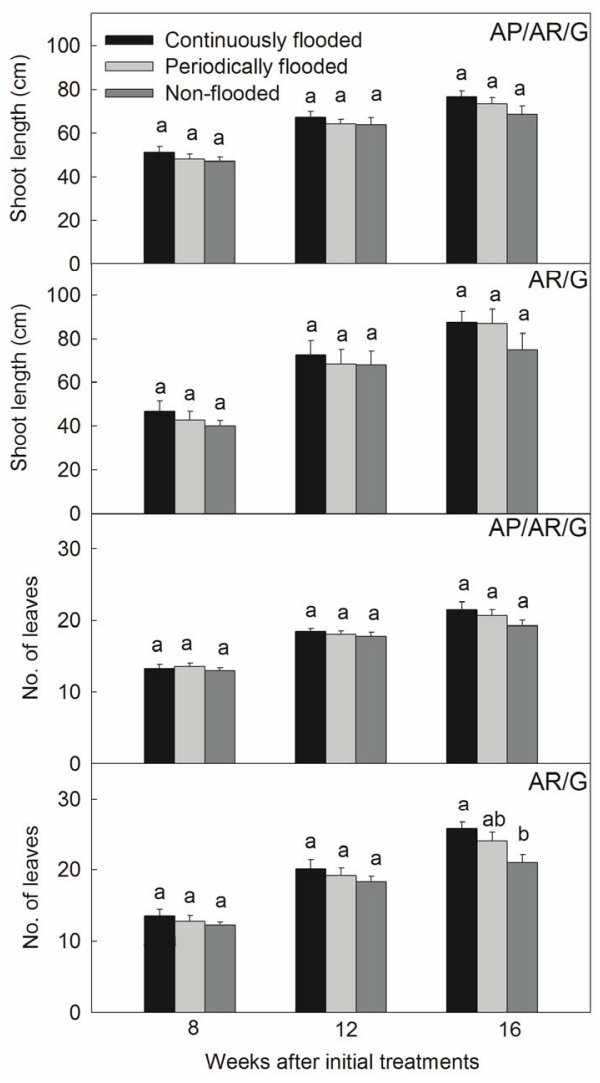

Figure 3. Shoot growth of $\mathrm{AP} / \mathrm{AR} / \mathrm{G}$ and $\mathrm{AR} / \mathrm{G}$ plants in response to continuous and periodic flooding (on Week 8, 12 and 16). Different letters indicate significant differences between flooding treatments according to LSD test $(\mathrm{P}<$ $0.05)$.

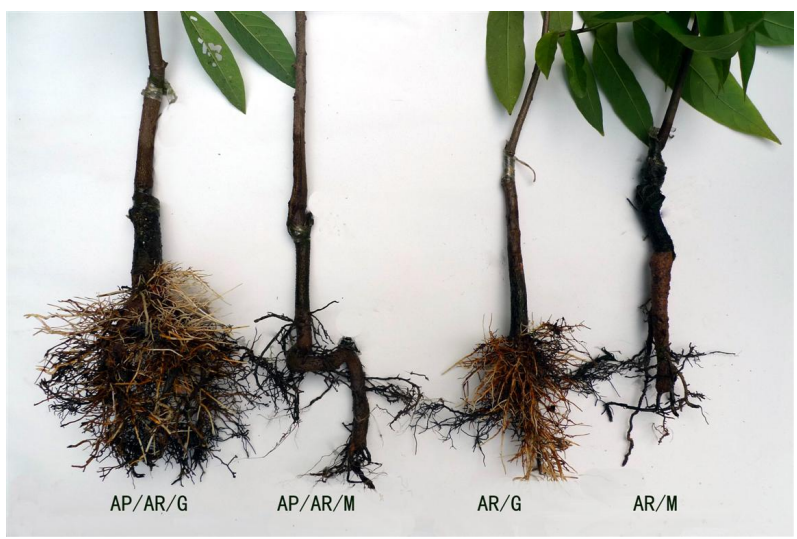

Figure 4. Morphology of root system of four annona scion/ rootstock combinations after 4 weeks of continuous flooding.

plants exposed to continuous flooding were much larger than those of non-flooded plants (Figure 5), suggesting that roots grew more vigorously under flooding in plants on $\mathrm{G}$ rootstock. Figures $\mathbf{4}$ and $\mathbf{5}$ also show that the root systems of AP/AP/G plants were larger than those of AR/ $\mathrm{G}$ plants in flooding or non-flooding groups. Hence, scion genotype also exerts substantial influence on root growth of the rootstocks.

\subsection{Photosynthesis}

For ruling out the environment effects on the net photosynthetic rates $(\mathrm{Pn})$ during the treatments, relative $\mathrm{Pn}$ against the level of the non-flooded control, which was always set as $100 \%$ in each scion/rootstock combination, was adopted for evaluating the effect of flooding treatments on Pn (Figure 6).

In the continuously flooded plants of $\mathrm{AP} / \mathrm{AR} / \mathrm{M}$ and AR/M, relative Pn declined constantly to $17 \%$ and $27 \%$ compared to the corresponding controls at Week 4, respectively. In the periodically flooded plants of $\mathrm{AP} /$ $\mathrm{AR} / \mathrm{M}$ and $\mathrm{AR} / \mathrm{M}$, Pn declined within 2 weeks during the flooding period to about half of the control level, but during the non-flooding period in Week 3 and 4, Pn recovered, the recovery in AR/M being faster than in $\mathrm{AP} /$ AR/M. Therefore, flooding caused significant decline in $\mathrm{Pn}$ in plants grafted onto M rootstock.

In contrast, flooding treatments did not cause Pn to decline in plants grafted on $\mathrm{G}$ rootstock, instead, the treatments tended to increase it especially in $\mathrm{AP} / \mathrm{AR} / \mathrm{G}$ plants. Pn in the continuously flooded AP/AR/G plants fluctuated above the control levels from Week 1 to Week 8 with the greatest difference at Week 2, when Pn was 2.5 times as high as the control level, but it decreased to the control level from Week 12 onwards. In the continuously flooded AR/G plants, Pn fluctuated around the control level, although it doubled the control level at Week 2. It seems that response of $\mathrm{Pn}$ in $\mathrm{AP} / \mathrm{AR} / \mathrm{G}$ to flooding was more pronounced than that in $\mathrm{AR} / \mathrm{G}$. 


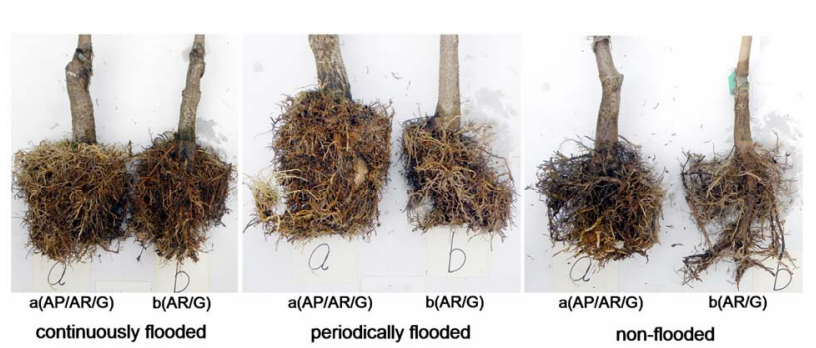

Figure 5. Root architecture of $\mathrm{AP} / \mathrm{AR} / \mathrm{G}$ and $\mathrm{AR} / \mathrm{G}$ after 16 weeks of exposure to flooding.

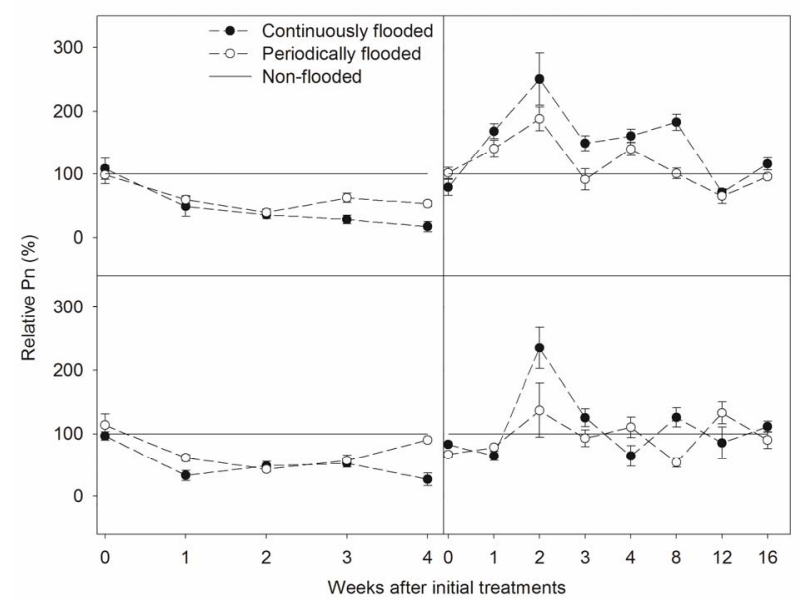

Figure 6. Effect of continuous and periodic flooding on relative net photosynthetic rates $(\mathrm{Pn})$ in four annona scion/rootstock combinations. Data points represent means of 3 replicates $\pm \mathrm{SE}$.

In periodically flooded plants of AP/AR/G, Pn increased within the first 2-week flooding period, but dropped to the control level at Week 3 after the first week of the subsequent non-flooding period. In the second week of the non-flooding period, Pn increased again and became significantly higher than the control level at Week 4. However, during later cycles of flooding and non-flooding treatments, Pn became less responsive to soil water changes and fluctuated around the control level. Pn in $\mathrm{AR} / \mathrm{G}$ was much less responsive to periodic flooding as compared to that in $\mathrm{AP} / \mathrm{AR} / \mathrm{G}$ and slightly fluctuated around the control level throughout the 16 weeks of the study.

\subsection{The Maximum Quantum Yield of PSII Photochemistry $\left(F_{v} / F_{m}\right)$}

At beginning of the experiment, $F_{\mathrm{v}} / \mathrm{F}_{\mathrm{m}}$ was around 0.84 and showed no significant difference among plants on different rootstocks or subjected to different treatments (Figure 7). In flooded plants of $\mathrm{AP} / \mathrm{AR} / \mathrm{M}$ and $\mathrm{AR} / \mathrm{M}, \mathrm{F}_{\mathrm{v}} / \mathrm{F}_{\mathrm{m}}$ maintained close to the control levels during the first week but became lower than the control levels as flooding continued. When flooding was removed in periodic flooding treatment after two weeks, $F_{v} / F_{m}$ in

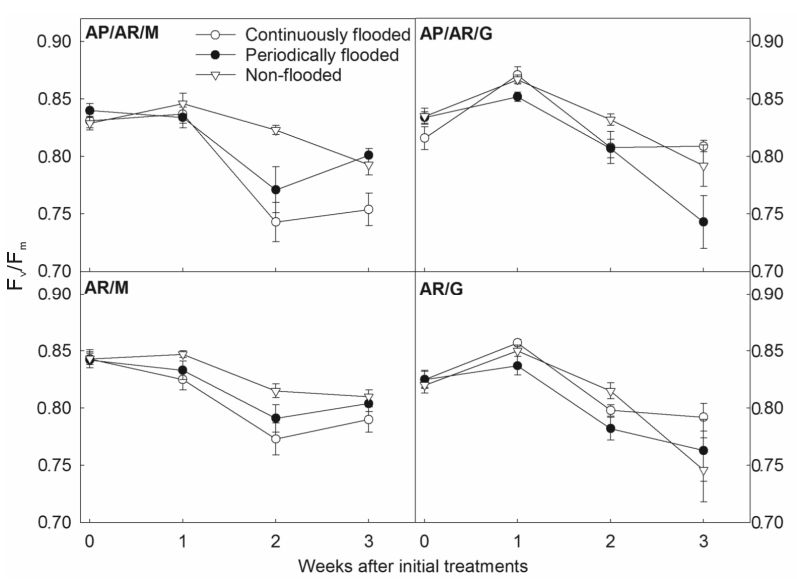

Figure 7. Effect of continuous and periodic flooding on $\mathrm{F}_{\mathrm{v}} / \mathrm{F}_{\mathrm{m}}$ of four annona scion/rootstock combinations. Data points represent means of 3 replicates $\pm \mathrm{SE}$.

both $\mathrm{AP} / \mathrm{AR} / \mathrm{M}$ and $\mathrm{AR} / \mathrm{M}$ recovered to the control levels. Flooding basically showed no significant effect on $F_{v} / F_{m}$ in $\mathrm{AP} / \mathrm{AR} / \mathrm{G}$ and $\mathrm{AR} / \mathrm{G}$. Interestingly, when $\mathrm{AP} / \mathrm{AR} / \mathrm{G}$ plants were removed from the two-week period of flooding, $\mathrm{F}_{\mathrm{v}} / \mathrm{F}_{\mathrm{m}}$ dropped below the control level, coinciding with a drop in Pn at the same period (Figure 6).

\section{DISCUSSIONS}

Fruit trees are generally propagated via vegetative methods, among which grafting is commonly used. As the scion contributes the canopy, the rootstock provides the root system, and interstock, if used, makes up part of the trunk. A grafted fruit tree is a combination of traits from two or three genotypes. Rootstocks exert a substantial effect on top growth by influencing the tree's mineral nutrition status, water status or hormonal status $[12,13]$. Hence, proper choice of rootstock provides a handy method to improve tree performance especially adaptation to soil conditions.

Flooding causes oxygen deprivation in the soil and thus loss of function and even death of the root system. Morphological changes related to flooding stress are growth decline and wilting [14-16]. However, trees show genetic differences in adaptation to flooding [17].

Among the annona members, A. glabra (G) was reported to be well adapted to flooding conditions $[7,9,18]$. A. montana (M) was also found to survive longterm flooding [18]. Annona atemoya is a highly valued fruit crop but sensitive to flooding $[9,18]$, which restricts its development in wetlands in South China. The grafting incompatibility between A. atemoya and $\mathrm{G}$ or $\mathrm{M}$ has been suggested to be overcome by applying the interstock of hybrid of A. atemoya $\times A$. reticulata (AR) $[9,19]$. In this study, AR was used both as scion and as interstock on $\mathrm{G}$ or $\mathrm{M}$, and again proved to be compatible to AP, G and M. In this way, a flood tolerant root system 
of $\mathrm{G}$ or $\mathrm{M}$ could be added to an AP tree.

Our study showed that plants with $\mathrm{G}$ and $\mathrm{M}$ rootstocks displayed great difference in adaptability to flooding, which was reflected by their difference in shoot growth. The differences in shoot growth rates appeared to be correlated with differences in root status, due to the complementary functions of shoots and roots on nutritional and hormonal basis [20,21]. Growth of plants on M rootstocks was significantly suppressed by continuous or periodic flooding (Figure 2), and wilting started to occur from the first week (Table 1). After 4 weeks of flooding, AP/AR/M plants had a higher wilting percentage as well as more severe wilting symptoms than AR/M plants, suggesting the difference in tree performance under flooding stress between scion genotypes. Flooding typically results in inhibited root growth of most woody plants [2]. Likewise, flooding reduced root growth of $\mathrm{AP} / \mathrm{AR} / \mathrm{M}$ and $\mathrm{AR} / \mathrm{M}$ by inhibiting new root formation, and the existing roots became dark brown (Figure 4), which is a sign loss of function or death of roots. Hence, in response to flooding, $\mathrm{M}$ rootstock adopts the strategy to minimize root growth and function, a common way to compensate for reduced energy supply due to anaerobic respiration under oxygen deprivation by water logging [3]. As a result, shoot growth and photosynthesis were inhibited. Based on the morphological and physiological responses to flooding, $\mathrm{M}$ is a flood sensitive rootstock and is not suggested to be applied in wetlands where flooding frequently occurs. However, the wilted plants on $\mathrm{M}$ did not die but regenerated new shoots after 16 weeks of continuous flooding. A previous study also showed that $\mathrm{M}$ survived 12 month of flooding with reduced growth [18].

In contrast, plants on $\mathrm{G}$ rootstock maintained vigorous growth under flooding treatments. However, during the first 4 weeks of flooding, shoot elongation and leaf production were suppressed especially in AR/AR/G plants (Figure 2). Thereafter, vegetative growth in flooded plants became faster than the control (Figure 3). The temporarily suppression of shoot extension and leaf production before Week 4 might be due to the sharp change of soil environment imposed by flooding. It might take some time for the flooded plants to acclimatize to the changed soil conditions, when plants allocate more resources to the root system. In consistency with this suggestion, a large number of active white roots were found in flooded $\mathrm{AP} / \mathrm{AR} / \mathrm{G}$ and AR/G plants on Week 4 (Figure 4), which outweighed the root number/mass of non-flooded plants on Week 16 (Figure 5). G rootstock seems to take quite a different strategy from that of $\mathrm{M}$ rootstock in response to flooding, namely by enhancing root growth.

The formation of active adventitious roots under flooding has been also observed in other flood tolerant plants [22-24] and can be regarded as a positive mechanism in response to flooding. In consistence with the result of
Nunez-Elisea et al. [9], we also observed swelled basal stem and hypertrophied stem lenticels in flooded plants on A. glabra. Nunez-Elieza et al. [9] found that flood tolerance of this species did not involve parenchyma formation in the stem, suggesting other mechanisms were functioning for roots to tolerate flooding conditions. Kreuzwieser et al. [3] suggested the steady supply of carbohydrates to the roots in order to maintain alcoholic fermentation for constant supply of energy and the avoidance of the accumulation of the toxic products of fermentation e.g. ethanol and acetaldehyde. They hypothesized a mechanism to avoid accumulation of toxic ethanol, which involves: 1 ) removal of ethanol from root into the leaves via the transpiration stream, 2) conversion of ethanol into acetyl-CoA in the leaves, and 3) acetyl-CoA incorporation into the plant's general metabolism. For such a mechanism to function, maintenance of leaf transpiration is important. In this study, leaves of $\mathrm{AP} / \mathrm{AR} / \mathrm{G}$ and $\mathrm{AR} / \mathrm{G}$ plants maintained turgid (Figure 1), which is a sign of fully opened stomata. Pathways converting and utilizing ethanol in $\mathrm{G}$ leaves are well worth exploring in order to understand the mechanism of its strong flooding tolerance.

As shown in Figures $\mathbf{3}$ and 5, growth of both shoots and roots of plants on $G$ rootstock were enhanced by continuous flooding. However, periodic flooding of these plants led to reduced shoot elongation and leaf production (Figure 3). In this regard, G is not only a flood tolerant rootstock but a flood loving one.

Both net photosynthetic rates and $\mathrm{F}_{\mathrm{v}} / \mathrm{F}_{\mathrm{m}}$ are sensitive indicators to show effects of stresses [11]. Rapid reduction in net photosynthetic rates of AP/AR/M and AR/M subjected to flooding was detected, which may be attributed to the closing of stomata or impairment of photosynthetic capacity $[2,25]$. However, the Pn was increased in flooded $\mathrm{AP} / \mathrm{AR} / \mathrm{G}$ and $\mathrm{AR} / \mathrm{G}$ plants compared to controls. Similarly, Mielke et al. [8] demonstrated that G seedlings had the capacity to maintain high stomatal conductance and net photosynthetic rates under soil flooding, although they found flooding induced decreases in Pn. The increase in Pn observed in our study satisfied the carbon demand for flood enhanced growth of both roots and shoots in AP/AR/G. Interestingly, Pn in periodically flooded plants of $\mathrm{AP} / \mathrm{AR} / \mathrm{M}$ and $\mathrm{AR} / \mathrm{M}$ recovered during non-flooded periods (Figure 6), suggesting that 2 week periods of flooding did not cause irreversible impairment of photosynthetic apparatus, and leaves were able to recover to relatively normal gas exchange levels when flooding stress is removed [26,27]. In contrast, there was a post-flooding drop in Pn in periodically flooded plants of $\mathrm{AP} / \mathrm{AR} / \mathrm{G}$ and $\mathrm{AR} / \mathrm{G}$ after removal of flooding treatment, indicating that Pn of plants on G rootstock can acclimatize to continuous flooding.

Compared to $\mathrm{Pn}$, drop of $\mathrm{F}_{\mathrm{v}} / \mathrm{F}_{\mathrm{m}}$, which indicates pho- 
toinhibition, seemed less responsive to flooding. $F_{v} / F_{m}$ was reduced by flooding in plants on $\mathrm{M}$ rootstock but the reduction was only significant in the second week of flooding treatment (Figure 7). Once the plants returned to the non-flooded status, $\mathrm{F}_{\mathrm{v}} / \mathrm{F}_{\mathrm{m}}$ recovered to the control levels (Figure 7). A similar recovery of $\mathrm{F}_{\mathrm{v}} / \mathrm{F}_{\mathrm{m}}$ to the control levels after the soil was drained was found in flooded field bean seedling [28], indicating that photoinhibition caused by flooding was highly reversible and photochemical reactions were not severely damaged. Other researchers [29,30] reported on other plants that flooding does not necessarily damage the photosynthetic apparatus $[29,30]$. However, in plants with $G$ rootstock, $F_{v} / F_{m}$ was not significantly affected. In all scion/rootstock combinations, $F_{\mathrm{v}} / \mathrm{F}_{\mathrm{m}}$, unlike $\mathrm{Pn}$, did not fluctuated greatly between flooded and non-flooded conditions. Therefore, $\mathrm{F}_{\mathrm{v}} / \mathrm{F}_{\mathrm{m}}$ is not a sensitive indicator for the effects of flooding on photosynthesis in annona species.

\section{CONCLUSION}

Flooding condition is stressful for annona plants on $\mathrm{M}$ rootstock, where growth and photosynthesis were suppressed by flooding. In contrast, flooding encouraged vegetative growth and photosynthesis in annona plants grafted on $\mathrm{G}$ rootstock. Scion genotype also influenced root growth of the rootstock. AP intergrafted with AR on $\mathrm{G}$ rootstock is a useful combination for regions with frequent soil flooding.

\section{REFERENCES}

[1] Jackson, M.B and Colmer, T.D. (2005) Response and adaptation by plants to flooding stress. Annuals of Botany, 96, 501-505. doi:10.1093/aob/mci205

[2] Kozlowski, T.T. (1997) Responses of woody plants to flooding and salinity. Tree Physiology Monograph, 1, 1-29.

[3] Kreuzwieser, J., Papadopoulou, E. and Rennenberg, H. (2004) Interaction of flooding with carbon metabolism of forest trees. Plant Biology, 6, 299-306. doi:10.1055/s-2004-817882

[4] Pezeshki, S.R. (2001) Wetland plant responses to soil flooding. Environmental and Experimental Botany, 46, 299-312. doi:10.1016/S0098-8472(01)00107-1

[5] George, A.P., Nissen, R.J. and Brown, B.T. (1987) The custard apple. Queensland Agricultural Journal, 113, 287297.

[6] Schaffer, B., Davies, F.S. and Crane, J.H. (2006) Responses of subtropical and tropical fruit trees to flooding in calcareous soil. Hortscience, 41, 549-555.

[7] Nunez-Elisea, R., Schaffer, B., Fisher, J.B., Colls, A.M. and Crane, J.H. (1999) Influence of flooding on net $\mathrm{CO}_{2}$ assimilation, growth and stem anatomy of annona species. Annuals of Botany, 84, 771-780.

doi:10.1006/anbo.1999.0977
[8] Mielke, M.S., Matos, E.M., Couto, V.B., De Almeida, A.F., Gomes, F.P,. Mangabeira, P. and Antonio, O. (2005) Some photosynthetic and growth responses of Annona glabra L. seedlings to soil flooding. Acta Botanica Brasilica, 19, 905-911. doi:10.1590/S0102-33062005000400025

[9] Nunez-Elisea, R., Schaffer, B., Crane, J.H and Colls, A.M. (1998) Impacts of flooding on annona species. Proceedings of the Florida State Horticultural Society, 111, 317319.

[10] Ojeda, M., Schaffer, B. and Davies, F.S. (2004) Flooding, root temperature, physiology and growth of two annona species. Tree Physiology, 24, 1019-1025. doi:10.1093/treephys/24.9.1019

[11] Maxwell, K. and Johnson, G.N. (2000) Chlorophyll fluorescence-A practical guide. Journal of Experimental Botany, 51, 659-668. doi:10.1093/jexbot/51.345.659

[12] Aloni, B., Cohen, R., Karni, L., Aktas, H. and Edelstein, M. (2010) Hormonal signaling in rootstock-scion interactions. Scientia Horticulturae, 127, 119-126. doi:10.1016/j.scienta.2010.09.003

[13] Basile, B., Marsal, J., Solar, L.I., Tyree, M.T., Bryla, D.R, and Dejong, T.M. (2003) Hydraulic conductance of peach trees grafted on rootstocks with differing size-controlling potentials. Journal of Horticultural Science \& Biotechnology, 78, 768-774.

[14] Belloni, V. and Mapelli, S. (2001) Effects of drought or flooding stresses on photosynthesis xylem flux and stem radial growth. International Society Horticultural Science, 544, 327-333.

[15] Chen, H.J., Zamorano, M.F. and Ivanoff, D. (2010) Effect of flooding depth on growth, biomass, photosynthesis, and chlorophyll fluorescence of Typha domingensis. Wetlands, 30, 957-965. doi:10.1007/s13157-010-0094-y

[16] Fernandez, R.T., Perry, R.L., Flore, J.A. and Mclean, R.M. (1997) Photosynthesis, 14C-photosynthate distribution and shoot and root growth of young apple tress on 3 rootstocks exposed to flooding. International Society Horticultural Science, 451, 351-359.

[17] Schmull, M. and Thomas, F. (2000) Morphological and physiological reactions of young deciduous trees (Quercus robur L., Q. petraea [Matt.] Liebl., Fagus sylvatica L.) to waterlogging. Plant and Soil, 225, 227-242. doi:10.1023/A:1026516027096

[18] Peng, S.X., Yang, S., Wan, J.X., Xie, Z.S., Wang, Z.H. and Li, J.G. (2009) A preliminary comparison of flooding tolerance among several annona species. Fujian Fruits, 2, 11-14 (in Chinese).

[19] Peng, S.X. and Huang, C.X. (1991) Primary study on the rootstocks of Atemoya (Annona. atemoya Hort.). Journal of South China Agricultural University, 12, 89-90 (in Chinese).

[20] Scheible, W., Lauerer, M., Schulze, E., Caboche, M. and Stitt, M. (1997) Accumulation of nitrate in the shoot acts as a signal to regulate shoot-root allocation in tobacco. The Plant Journal, 11, 671-691. doi:10.1046/j.1365-313X.1997.11040671.x

[21] Wilson, J.B. (1988) A review of evidence on the control 
of shoot: Root ratio, in relation to models. Annuals of Botany, 61, 433-449.

[22] De Oliveira, V. and Joly, C. (2010) Flooding tolerance of Calophyllum brasiliense Camb. (Clusiaceae) morphological physiological and growth responses. Trees-Structure and Function, 24, 185-193. doi:10.1007/s00468-009-0392-2

[23] Else, M.A., Janowiak, F., Atkinson, C.J. and Jackson, M.B. (2009) Root signals and stomatal closure in relation to photosynthesis, chlorophyll a fluorescence and adventitious rooting of flooded tomato plants. Annuals of Botany, 103, 313-323. doi:10.1093/aob/men208

[24] Islam, M.R., Hamid, A., Khaliq, Q.A., Haque, M.M., Ahmed, J.U. and Karim, M.A. (2010) Effects of soil flooding on roots, photosynthesis and water relations in mungbean (Vigna radiata (L.) Wilczek). Bangladesh Journal of Botany, 39, 241-243.

[25] Herrera, A., Tezara, W., Marin, O. and Rengifo, E. (2008) Stomatal and non-stomatal limitations of photosynthesis in trees of a tropical seasonally flooded forest. Physiologia Plantarum, 134, 41-48. doi:10.1111/j.1399-3054.2008.01099.x

[26] Joyner, M.E. and Schaffer, B. (1989) Flooding tolerance of "golden star" carambola trees. Proceedings of the Florida State Horticultural Society, 102, 236-239.

[27] Nickum, M.T., Crane, J.H., Schaffer, B. and Davies, F.S. (2010) Reponses of mamey sapote (Pouteria sapota) trees to continuous and cyclical flooding in calcareous soil. Scientia Horticulturae, 123, 402-411. doi:10.1016/j.scienta.2009.09.021

[28] Pociecha, E., Koscielniak, J. and Filek, W. (2008) Effects of root flooding and stage of development on the growth and photosynthesis of field bean (Vicia faba L. minor). Acta Physiologia Plantarum, 30, 529-535. doi:10.1007/s11738-008-0151-9

[29] Jing, Y.X., Li, G.L., Gu, B.H., Yang, D.J., Xiao, L., Liu, R.X. and Peng, C.L. (2009) Leaf gas exchange, chlorophyll fluorescence and growth responses of Melaleuca alternifolia seedlings to flooding and subsequent recovery. Photosynthetica, 47, 595-601. doi:10.1007/s11099-009-0085-5

[30] Li, M., Yang, D. and Li, W. (2007) Leaf gas exchange characteristics and chlorophyll fluorescence of three wetland plants in response to long-term soil flooding. Photosynthetica, 45, 222-228. doi:10.1007/s11099-007-0036-y 